\title{
Sustainable development management of industrial fruit growing
}

\author{
Evgeniy Egorov ${ }^{1}$, Zhanna Shadrina ${ }^{1}$, Gayane Kochyan ${ }^{1, *}$, and Vladimir Kudryakov ${ }^{2}$ \\ ${ }^{1}$ Federal State Budgetary Scientific Institution "North Caucasus Federal Scientific Center for \\ Horticulture, Viticulture, Winemaking”, 40-letiya Pobedy st., 39, 350901 Krasnodar, Russian \\ Federation \\ ${ }^{2}$ Federal State Budgetary Educational Institution of Higher Education "Kuban State Agrarian \\ University named after I.T. Trubilin”, Kalinina st., 13, 350044 Krasnodar, Russian Federation
}

\begin{abstract}
Methodical approaches to the organization and management of reproduction processes stability were presented. A specific conceptual apparatus has been developed; it reflects the functional load of a number of concepts and, first of all, fundamental ones, such as system-wide and functional stability, management development of industry production and the sustainability of reproduction processes. The characteristic of the current problems that constrain the sustainable development of industrial fruit growing was given: negative influence of macroeconomic factors, insufficiently effective regulation of fruit and berry products market, lack of considered and systematically realizable varietal, technological and phytosanitary policy, unlimited use when laying plantations of imported varietal planting material and oculants, continuing significant changes in climatic conditions. The main disproportions and imbalances in the reproduction processes organization were established. The dimensionality of resources required for sustainable development was calculated. The main regulators of sustainable development management, methods of bringing the system into a stability state and reproduction efficiency were presented.
\end{abstract}

\section{Introduction}

The development of the fruit and berry AIC subcomplex in the conditions of the necessity to ensure the country's food security is the most important priority in Russia's agrarian policy. The main goal of the horticulture industry development is to increase the own production volume of industry products, resource and technological support of industry reproduction processes, economic basis formation of territorial entities.

Industrial fruit growing is a complex natural-technogenic system formed with the participation of various subsystems (biological, technogenic and economic), which is influenced by many factors (macroeconomic, technological, climatic, market), necessitating the development of adequate measures to ensure the reproduction processes' sustainability in industry production and increase of their efficiency, ensuring stable profitability within the production and technological system.

\footnotetext{
* Corresponding author: gayanek@mail.ru
} 
Sustainable development of complex-organized natural and technological systems is a consistent increase of system capabilities under the influence of changing internal and external environment factors to provide an increase in quantitative and qualitative indicators, to carry out the reproduction of products, means of production, natural resources, environment mainly at the expense of its own opportunities.

\section{Materials and methods}

In the substantiation of the main management regulators of reproduction processes' sustainable development, methods of system, management by objectives, calculationanalytical, modeling complex processes and information systems were used. Methodical tools for optimization of reproduction processes contains analytical, structural and mathematical apparatus using multidimensional information arrays in the subject fields of research and digital ways of processing empirical data. The application of these methods was based on their functional capabilities, which ensured the adequacy and verifiability of the obtained results for the formation of the main control regulators of reproduction processes' stability and determination of their optimal dimension.

\section{Results and discussions}

The main factors influencing the industry products' production efficiency and determining the reproduction capabilities of industry processes, the set of which is realized in optimal design and regulatory solutions and provided by the necessary regulators are: macroeconomic; market; resource; technological (production).

The main macroeconomic factors affecting the performance and sustainability of reproduction processes in the subject of industrial fruit production are: macroeconomic situation characterized by the inflation rate, the cost of a dual currency basket, on the which dimension influences the level of individual structural elements of production costs, as well as the shape and dimension of the existing State support for domestic agricultural producers (Figure 1).

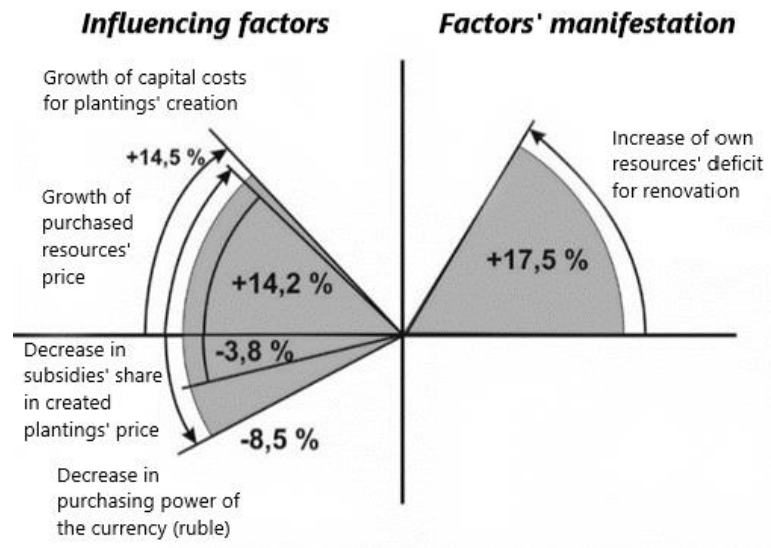

Fig. 1. Influence of macroeconomic factors on the development of industrial fruit production subjects for 2010-2020

The size of supply and demand, the pricing system, the level of competition and competitiveness are the main market factors influencing the sustainability of industry development. To characterize the influence of market factors on the performance and 
sustainability of reproduction processes, the following system of indicators is used: the capacity of market industry segments, correlation and regression dependencies of sales volumes and price level, indicators of sales seasonality of industry products [1].

Resource factors influence the efficiency of reproduction processes' organization in industry entities and are characterized by the necessary and sufficient means amount of production and labor for their effective activities' implementation [2, 3].

Technological (production) factors - means of production, forms, methods (agrocenoses' structures), mechanisms (operational regulations) of organization and reproduction processes' implementation reflecting changes in production technologies [4].

The specific stability of reproduction processes in industrial fruit growing is characterized by the availability of necessary resources types, their scope of application, ways and methods of their transformation, functional relationships and interactions between the various factors that contribute to the efficiency of industry production.

The main types of reproduction processes' sustainability in industrial fruit production include: system-wide and functional (Functional system stability is formed by establishing indicators of subsystem elements state and bringing them to the normative value, optimal range, specific methods, methods, forms [3].) (technological and economic, financial and economic, environmental and economic) sustainability.

Technological and economic stability is characterized by rational realization sufficiency of productive potential of agrocenosis and economic resources' costs, providing a given reproduction level (production profitability level not less than 60\%).

Financial and economic stability is the resulting comparability of financial and economic indicators and total resource costs for production and sales of industry products, which ensures sufficient efficiency (with a level of profitability corresponding to enhanced reproduction) and production competitiveness.

Ecological and economic stability is an optimal balanced possibility of biological and economic resources, ensuring the functioning of the system (process) in a given mode.

Emerging imbalances in the reproduction processes' organization in industry production, primarily due to negative influence of macroeconomic factors and functional imbalances in the production activities' implementation of specialized fruit organizations, actualize the need to develop adequate measures to ensure the sustainability of production and technological processes and leveling negative influences from their impact [5].

Sustainable development of industrial fruit growing, that is, the provision of a given level of reproduction, initially requires: an optimizing approach to structural organization that considers soil - climatic and varietal specifics; operational regulation of the structure of plantings and individual agrocenoses; regulatory methods in managing resource costs; proportionality, harmonization and comparability of structural elements; state regulation of macroeconomic imbalances that constrain development.

Development management - a system of principles and requirements of the organization subordinate by unified goal-setting, the structural and resource organization of reproduction processes, as well as methods and ways of development and implementation of managerial decisions aimed at achieving and ensuring the sustainability of their functioning in a given regime [6-9].

Development management of industrial fruit growing and reproduction processes' sustainability is based on the algorithm for managing the factors most influencing sustainable production development. The implementation of this algorithm involves the use of tools containing management methods, criteria, and principles of sustainable production organization, specified limiters associated with specifics of price interrelations and technological and economic inter-influences, mathematical apparatus and statistical verification of models.

The most urgent problems that constrain the development of industrial fruit growing are: 
- macroeconomic processes (factors) that form trends deforming the reproduction stability in industrial fruit production, which leads to a decrease in production efficiency and reduction of agricultural producers' own funds on the renovation of fixed production funds including plantings and provision of production processes. Thus, the increase in the cost of acquired resources is on average $8 \%$ per year, the increasing shortage of own resources in agricultural enterprises (organizations) for current activities - $40 \%$, ahead of the growth rate of production costs averaging to 0.4 percentage points, real production efficiency decreases by more than $3 \%$ a year. Cost disparities lead to an increase in the costs of laying plantations (2.5 times for the 2010-2020 period), reduce the share of budget subsidies in the costs of laying plantations by an average of 3.8 points;

- insufficiently effective regulation of the fruit and berry products market, the monopoly position of chain retailers in the market has led to a trend when agricultural producers are deprived of most of added value, retail prices for fruit products in the retail network are more than twice the average wholesale purchase price of agricultural producers. Failure to take measures on customs regulation of seasonal market capacity by non-tariff methods leads to its overstocking by imported products, limits the implementation opportunities of domestic producers, which, in turn, leads to a significant decrease in their yield (by an average of 12 points per year), increases the burden on the regional and federal budgets for subsidies of laying plantings due to the increasing shortage of own funds of agricultural producers;

- the absence of a verifiable, firstly considering the zonal soil-climatic conditions of fruit and berry crops cultivation and systemically realizable varietal (optimal number of varieties in agrocenoses, breed and variety composition, varietal seasonal conveyors), technological (rootstock, rootstock-scion combinations, methods of cultivation, breed and seasonal conveyors), as well as phytosanitary policy cause significant economic losses: the death (partial or full) of plantings, low yield compared to the project, as a result of epiphytoties caused by various diseases and pests distributed by imported planting material. Thus, laying plantings with insufficiently adapted and often infected planting material leads to an increase in losses (partial death) to $2-3 \%$ on average per year. Financial losses from the plantings laying with unadapted planting material are more than 700 million rubles in the whole of the Russian Federation in the prices of 2020, which is $15 \%$ of the annual budget subsidies for laying plantations (2019 4,6 billion rub. of subsidies). In plantings with noncompliance with varietal agrotechnics, there is a decrease in yield of up to $20 \%$ on average. The amount of underreceived income is on average 168 thousand rub./ha per year (in 2020 prices). The cost of protective measures in plantings having no compliance with varietal agrotechnics increases by 17 thousand rub./ha or $13.8 \%$ on average per year. The total amount of financial losses from excess varieties in agrocenoses is 162 thousand rub./ha or $22.3 \%$ of the average financial result value of agricultural producers (sales proceeds).

- unlimited use of imported varietal planting material and oculants $(40 \%$ on average per year) in laying plantations along with positive points (varietal changing, market demand satisfaction for products of certain varieties, etc.) causes the spread and epiphytotic manifestation of diseases and pests previously not observed in domestic gardens, restrains the development of domestic seedlings production of the highest quality categories, causes high import costs, forms a consistently high import dependence. Every year the cost of purchasing imported seedlings is more than 3 billion rubles, the cost of imported seedlings is 2.2 times higher than the cost of domestic seedlings with the same quality parameters;

- the continued significant change in climatic conditions, especially the increase in the average annual ground surface air temperature (more than $1.5^{\circ} \mathrm{C}$ for the period of 1997 2020) places special requirements on conformity of technologies, varietal-rootstock combinations to zonal climatic conditions, and the increase in the amplitude of climatic 
manifestations leading to frequent hail damage situations necessitated the need for creating support structures for the installation of hail-protective grids, which increases the cost of laying one hectare by 300 thousand rubles or $27 \%$, which in turn also determines the need to increase the amount of subsidies;

- $\quad$ significant amount of imported varietal planting material use, non-observance of varietal and technological discipline, failure to consider zonal soil-climatic features leads to violation in fruit crops cultivation technologies (non-realizability of the variety's productive potential, loss of plantings, increase in costs for protective measures, increase in chemical pressure to agroecosystems, etc.) causes not only significant loss of resources for the agrocenoses creation, but also a decrease in production efficiency — an increase in the cost of production, decrease in its quality due to failure to comply with regulations related to the shortage of own funds among agricultural producers. Thus, the growing deficit of own working capital on average per year by $2.4 \mathrm{p}$. or 200 thousand rub./ha causes a decrease in the fruit and berry products' production efficiency by more than 13 points per year.

Comparable assessment of actual and normative parameters of reproduction processes' functional stability in subjects of industrial fruit growing indicates existing imbalances in their organization, which necessitates the development of specific methods and ways for managing stability and efficiency, as well as tools for impact on reproduction processes' functional zones in order to bring actual indicators to the normative level [10].

The main regulators of sustainable development management in the subjects of industrial fruit production include: economic - parametric optimization and normative regulation of technological processes' production indicators; technical and technological - regulatory structuring of organized reproduction processes and operational management of reproduction processes; market - price mechanism improvement for increasing the fruit products' yield, regulation of the consumer market capacity (setting seasonal quotas for the period of mass harvest and sale); macroeconomic - instruments of state regulation of cost relationship.

Analysis and comparison of the actual indicators and the normative level of technological and economic, financial and economic, environmental-economic stability to ensure sustainability, stability and efficiency of production in the subject of industrial fruit growing indicates significant imbalances (table 1).

Table 1. Generalizing evaluation of functional stability of reproduction processes in industrial fruit growing (by group of specialized fruit organizations of Krasnodar Krai)

\begin{tabular}{|c|c|c|}
\hline \multirow{2}{*}{ Evaluation indicator } & \multicolumn{2}{|c|}{ Fruit growing } \\
\hline & normative value & actual value \\
\hline \multicolumn{3}{|c|}{ Technological and economic sustainability } \\
\hline Break-even threshold excess ratio & 3.6 & 4.0 \\
\hline Production costs comparable to income, $\%$ & no more than 58 & 76.9 \\
\hline Working capital turnover ratio & 4.21 & 3.9 \\
\hline Enhanced reproduction rate, $\%$ & 14.2 & 6.0 \\
\hline Cumulative indicator of technological and economic sustainability & $0.845-1.0$ & 0.741 \\
\hline \multicolumn{3}{|l|}{ Financial and economic stability } \\
\hline Production costs, thousand rub./ha & $699.2-888.2$ & 854.8 \\
\hline Profit from sales, thousand rub./ha & $361-550.7$ & 256.1 \\
\hline The value of working capital, thousand rub./ha & $283.3-384.5$ & 284.8 \\
\hline Direct to fixed cost ratio & 1.6 & 1.67 \\
\hline The level of products' profitability, $\%$ & 62.0 & 37.6 \\
\hline Cumulative indicator of financial and economic stability & $0.782-1.0$ & 0.517 \\
\hline Cumulative indicator of environmental and economic sustainability & $0.773-1.0$ & 0.679 \\
\hline Synergetic indicator of functional stability & $0.797-1.0$ & 0.659 \\
\hline
\end{tabular}


The main reasons for the non-conformity of the actual values and normative parameters of technological and economic stability indicators of reproduction processes in industrial fruit production is a shortage in material and financial resources for efficient productive production activities resulting from the normative excess of total costs relative to the income portion. The necessary and sufficient amount of material resources to ensure the normative level of technological and economic efficiency of reproduction processes should be at least 300 thousand rub./ha, which is 1.18 times more than the actual value of this indicator in 2020 , labor resources (costs for the wage fund formation) — not less than 330 thousand rub./ha or $125 \%$ of the actual level of 2020 . The main management methods of technological and economic stability of reproduction processes are: efficiency parameters optimization methods of industry products' production, standards of regulatory and structural decisions, regulations for management of production and technological processes' parameters, standards of system organization of conducting fruit growing.

Existing deformations in the reproduction processes' organization lead to a significant deficit of economic resources (for carrying out planned renovations of perennial plantings and updating production infrastructure funds, for the formation of working capital funds in order to carry out current production activities), as evidenced by the discrepancy of actual and regulatory values of financial and economic stability according to the specialized organizations' group of the fruit and berry subcomplex of the Krasnodar Krai AIC. This trend causes a decrease in the production and technological processes' efficiency in the subjects of industry production and a decrease in their reproduction capabilities. The necessary amount of financial resources for the negative consequences leveling caused by the unstable condition of the system is more than 180 thousand rub./ha in 2020 prices.

The assessment of ecological and economic stability is based on the following regularities: reduction of agrocenosis' production potential by $0.7 \%$ with growth of technogenic load by $1 \%$; decrease in the reproduction potential of fruit plants by $2.7 \%$ with an increase in pesticide load by $1 \%$; a decrease in production profitability by 0.3 percentage points with yield decrease by $1 \%$ due to negative effects of biotic and abiotic stress factors. When substantiating the optimal parameters of ecological and economic stability, the following limiters were also used: realization of agrocenosis' production potential up to $70 \%$, relative value costs - not more than $58 \%$, an excess of yield relative to the break-even threshold in the range of 2.3 to 2.7 . In order to achieve economically optimal production indicators (optimum yield level), it was found that the increase in additional costs for agro technological activities related to the reproduction potential restoration of plants, soil and the soil microbiota should amount to: $62.8 \mathrm{rub} . / \mathrm{cwt}$ (5.4\% growth) and 20.6 thousand rub./ha (17.0\% growth) respectively. This trend causes the decrease in efficiency of production and technological processes (production of industry products) by an average of 6.2-6.8 points and actualizes the need for developing agro-technological measures complex aimed at leveling the negative consequences of the ecological and economic factors' influence on the state of fruit agrocenosis.

\section{Conclusions}

Compliance with optimal parameters of stability and efficiency in the organization of reproduction processes in industrial fruit growing, application of scientifically-based tools for regulating development processes in optimal dimension considering macroeconomic, technological-economic and ecological-economic interrelations in complex natural and technogenic systems will ensure the achievement of functional system stability and high efficiency of production and technological processes. 


\section{Acknowledgement}

The study was carried out with the support of RFBR and the administration of the Krasnodar Krai No. 19-410-230026 r_a and within the framework of the state task of the Ministry of Education and Science of Russia.

\section{References}

1. V.M. Melkumyan, Bulletin of Moscow Regional Pedagogical University, "Economics" series, 2, 31 (2013)

2. Kh.A. Faskhiev, E.V. Popova, Marketing in Russia and abroad, 4, 53 (2003)

3. S.G. Ryzhuk, E.I. Ovachuk, Bulletin of Altai State Agrarian University, 11(97), 115 (2012)

4. O. M. Kalieva, N.V. Luzhnova, M.I. Dergunova, M.S. Govorova, Innovative economy: materials of the international scientific conference, 93 (2014)

5. E.A. Egorov, Zh.A. Shadrina, G.A. Kochyan, Science of Kuban, 1, 39 (2008)

6. J. H. P. P. Eustachio, A. C. F. Caldana, L. B. Liboni, D. P. Martinelli, Journal of Cleaner Production, 241 (2019)

7. L. Marrucci, T. Daddi, F. Iraldo, Journal of Cleaner Production, 240 (2019)

8. F. Hofmann, M. Jaeger-Erben, Business strategy and the environment, 29 (2020)

9. K. Lancker, A. -L. Deppenmeier, T. Demissie, J. O. Schmidt, PLoS ONE, 14(8) (2019)

10. E.A. Egorov, Zh.A. Shadrina, G.A. Kochyan, Optimization of reproduction processes in industrial fruit growing (2009) 